\title{
Religion and Education: \\ Evidence from the National Child Development Study
}

\author{
Sarah Brown and Karl Taylor* \\ Department of Economics \\ University of Leicester \\ University Road, Leicester \\ Leicestershire LE1 7RH \\ England
}

\begin{abstract}
In this paper, we explore the determinants of one aspect of religious behaviour - church attendance at the individual level using British data derived from the National Child Development Study (NCDS). To be specific, we focus on the relationship between education and church attendance, which has attracted some attention in the existing literature. In contrast to the previous literature in this area, our data allows us to explore the dynamic dimension to religious activity since the NCDS provides information on church attendance at three stages of an individual's life cycle. The findings from our cross-section and panel data analysis, which treats education as an endogenous variable, support a positive association between education and church attendance. In addition, our findings suggest that current participation in religious activities is positively associated with past religious activities. Furthermore, our findings suggest that levels of religious activity tend to vary less over time suggesting that factors such as habit formation may be important.
\end{abstract}

Key Words: Church Attendance; Education; Human Capital; Religion.

JEL Classification: J24, Z12

Acknowledgements: We are grateful to the Data Archive at the University of Essex for supplying the National Child Development Study, waves 1 to 6. The normal disclaimer applies.

*Corresponding author Dr Karl Taylor, email kbt3@le.ac.uk or Tel: +44 (0)116 2525368.

November 2003 


\section{Introduction}

Religious activity is one area of household behaviour that has attracted very little interest in the economics literature [Sawkins et al. (1997)]. Although the boundaries surrounding areas of economics have been widened, there has appeared to be some reluctance amongst economists to incorporate religion, although it has been argued that economic frameworks may provide the best contexts in which to model religious behaviour [Stark et al. (1996)]. Such reluctance is surprising since as argued by Iannaccone (1998):

\footnotetext{
Studies of religion promise to enhance economics at several levels: generating information about a neglected area of "nonmarket" behavior; showing how economic models can be modified to address questions about belief, norms and values; and exploring how religion affects economic attitudes and activities of individuals, groups and societies. [Iannaccone (1998), p.1465].
}

Over the last decade or so, there has been a mild flurry of interest into this expanding area of economics with most of the empirical work based on U.S. data [see Iannaccone (1998) for an excellent survey of the economics of religion]. One strand of the literature has employed microeconomic theory to explore the determinants of religious behaviour such as the decision to participate in religious activities - a decision that may vary over an individual's life cycle [Smith et al. (1998)].

The aim of this paper is to explore the determinants of one measure of religious activity - church attendance - at the individual level using British panel data derived from the National Child Development Study (NCDS). Moreover, we focus on one specific characteristic of individuals, which has been the subject of much scrutiny by economists over many decades - namely education. Iannaccone (1998) outlines a number of interesting questions, which have been raised concerning the relationship between religion and education in the context of secularisation. For example, is it the case that individuals become less religious and more sceptical of faith-based claims as they acquire more education? Is this 
more pronounced as individuals acquire more education in the sciences? Many studies have, however, reported that rates of religious activity such as church attendance in fact increase with education.

Despite the fact that many studies report a positive association between education and religious activity, as pointed out by Sander (2002) such findings do not mean that education actually increases religious activity. In general, the existing studies in this area have treated education as exogenous despite the early work by Azzi and Ehrenberg (1975) who argue that human capital variables should be treated as endogenous. Sander (2002) expands the existing research in this area by treating education as an endogenous variable and finds that there is no causal affect of education on religious activity using U.S. cross-section data.

In this paper, we build upon the approach of Sander (2002) in three main ways. Firstly, we expand the church attendance equation to incorporate a richer array of explanatory variables. Secondly, we drawn upon the recent economics of education literature and specify a more comprehensive educational attainment equation in order to control for endogeneity bias. Furthermore, in contrast to Sander (2002) who analyses years of education, we are able to explore an additional and perhaps preferable measure of educational attainment - namely highest educational qualification obtained. Thirdly, we analyse individual panel data thereby enabling us to explore religious activity from a dynamic perspective, i.e. at different points of an individual's life cycle.

The findings from our cross-section and panel data analysis support a positive association between education and church attendance. In addition, our findings suggest that current participation in religious activities is positively associated with past religious activities. Furthermore, our findings suggest that levels of religious activity tend to vary less over time suggesting that factors such as habit formation may be important. To summarise, our results suggest that a time dimension to religious activity exists. Furthermore, the 
importance of previous religious activity in determining current levels of religious activity suggests that omitting such factors from econometric analysis may lead to biased results and erroneous inferences.

The rest of the paper is set out as follows. Section II discusses the background issues surrounding the relationship between religion and education. Section III describes the data and methodology employed. Section IV presents the results of our empirical analysis whilst our concluding comments are collected in Section IV.

\section{Background}

In general, economists have explored the decision to engage in religious activity from the perspective of a time allocation model. Azzi and Ehrenberg (1975), for example, explored church attendance in the U.S. in the context of a household allocation of time model where participation in religious activity served to raise consumption in the 'afterlife.' This seminal contribution to the area has been modified and extended in a number of ways. One modification, for example, entails allowing religious activity to enhance current as well as 'afterlife' utility [see Iannaccone (1998)]. One of the key implications drawn from such a framework is that the time allocated to religious activity may initially fall then rise with age given that the opportunity cost of religious activity is initially high at the start of an individual's career when faced with a relatively steep age-earnings profile. As age increases, however, the age-earnings profile typically flattens thereby reducing the opportunity cost associated with religious activity [Sawkins et al. (1997)].

Thus, empirical studies have included a combination of personal characteristics such as age and labour market characteristics for example earnings as explanatory variables in regression models seeking to explain levels of religious activity such as church attendance. In general, cross-section data has been employed to explore religious activity. It is apparent, 
however, as indicated above that the time dimension plays an important role in the context of time allocation models with the costs of particular activities being sensitive to the stages of an individual's life cycle. Hence, the analysis of panel data would clearly be preferable in this context. However, the findings from the cross-section studies do provide some interesting insights into the determinants of religious activity at a given point in time.

Educational attainment plays an important role in determining the opportunity cost of engaging in activities such as religion. As argued by Brañas Garza and Neuman (2003), the predicted effect of schooling on religious activities is, however, somewhat ambiguous. If the opportunity cost of time devoted to religious activities is positively related to education, then one would predict an inverse relationship between religious activities and educational attainment. Furthermore, as outlined above, individuals may become less religious as education increases as they become more inclined to reject faith-based beliefs. Sacerdote and Glaeser (2002), however, argue that if education increases the returns from social activities, then one might predict a positive association between education and religious activities (i.e. a formal social activity). Barro and McCleary (2002) propose an alternative explanation for the positive association between religious activity and education - given that religious beliefs entail a degree of abstraction and that more educated individuals are relatively capable of scientific and abstract thought, they might be able to rationalise religious beliefs in this way.

Thus, given that the predicted effect of schooling on religious activities is somewhat ambiguous, empirical analysis is required to shed some light in this area. The empirical work in this area has predominantly used U.S. data. In general, church attendance has been found to be positively associated with educational attainment [see, for example, Iannaccone (1998) and Sacerdote and Glaeser (2002)]. Furthermore, Sacerdote and Glaeser (2002) state:

'In many multivariate regressions, education is the most statistically important factor explaining church attendance.' [Sacerdote and Glaeser (2002), p.2]. 
Sacerdote and Glaeser (2002) explore an interesting puzzle related to religious attendance in the U.S. where religious attendance increases sharply with education across individuals yet declines sharply with education across denominations with the more highly educated denominations being characterised by the lowest rates of church attendance. The key to explaining this puzzle lies in the existence of omitted variables, which differ across denominations. Furthermore, Sacerdote and Glaeser argue that the most likely omitted variable is the degree of religious beliefs and they provide evidence that measures of religious beliefs are strongly correlated with church attendance yet negatively correlated with education for a number of countries including the U.S. and Great Britain. Moreover, they provide some evidence of a causal link that education moderates religious beliefs. They also provide evidence supporting the hypothesis that the positive association between education and church attendance is due to omitted variables related to social skills and propensity to engage in formal social activities. The reasoning behind this is that schooling and church attendance are both formal social group activities - hence we would predict a positive correlation between the two activities.

Sacerdote and Glaeser provide cross-section evidence for the U.S. and throughout the world, indicating that education is positively associated with all forms of social behaviour, that religious attendance is correlated with other forms of social activity and that schooling is not correlated with non-social religious behaviour. In sum, according to these hypotheses, more educated individuals are more likely to attend church (i.e. to engage in this formal social activity) but are less likely to accept, for example, the literal truth of the bible. Sacerdote and Glaeser compare their U.S. findings based on the U.S. General Social Survey, across countries by analysing the World Values Survey. They find a positive relationship between education and church attendance at the individual level in Great Britain, Spain, Sweden and 
France, a negative relationship in other countries including Poland and Russia and a statistically insignificant relationship in a number of other countries.

Sawkins et al. (1997), one of the rare studies focusing on British data, find that church attendance is positively correlated with educational attainment when attendance equations are estimated separately for males and females using cross-section data derived from the first wave of the British Household Panel Survey. Similarly, Brañas Garza and Neuman (2003) who explore the level of religiosity as measured by beliefs, prayer and church attendance amongst Spanish Catholics by estimating separate equations for males and females, report a marginally significant positive relationship between schooling and religiosity. One of the important features of this study is that the data allows the authors to distinguish between private and public religious activity. To be specific, the positive relationship is statistically significant for women for both participation in mass (i.e. a public activity) and prayer (i.e. the private activity) yet only significant for men in the case of participation in mass.

Although a number of studies report a positive association between education and religious activity, ${ }^{1}$ as pointed out by Sander (2002) these findings do not necessarily mean that education is positively related to religious activity. In general, such studies have treated education as exogenous despite the early work by Azzi and Ehrenberg (1975) who argue that human capital variables should be treated as endogenous. Sander expands the existing research in this area by treating education as an endogenous variable and finds that there is no causal affect of education on religious activity using U.S. cross-section data. ${ }^{2}$

In the following section, we introduce the data and the empirical methodology employed to assess the impact, if any, educational attainment has on religious attendance in

\footnotetext{
${ }^{1}$ Neuman (1986) is one exception in the literature who reports an inverse relationship between schooling and time spent on religious activities among Jewish males in Israel. One of the defining features of this study is that unlike the majority of studies in this area, which rely on an index of church attendance, religiosity is measured by the total number of hours spent on religious activities.

2 The over-identifying instruments for the education equation used in Sander's analysis are parent's schooling.
} 
Great Britain. An advantage of our approach is that our data enables us to control for potential endogeneity effects, as highlighted by Azzi and Ehrenberg (1975) and Sander (2002), within a panel framework and, thus, to focus on an area unexplored in the literature to date, namely the dynamics of religious attendance.

\section{Data and Methodology}

Our empirical analysis is based on the British National Child Development Study (NCDS) which is a panel survey following a cohort of children born during a given week (March $3^{\text {rd }}$ to March $9^{\text {th }}$ ) in 1958 . This panel study provides a wealth of information relating to family background in addition to the advantages of tracing an individual over a relatively long time horizon. The Survey was conducted at ages 7, 11, 16, 23, 33 and 42.

The NCDS is particularly appropriate for our analysis since it provides information pertaining to church attendance in addition to detailed information relating to educational attainment. In terms of church attendance, respondents were asked the following question at three points during their life cycle - at ages 23, 33 and 42:

$\begin{array}{ll}\text { How often, if at all, do you attend services or meetings connected with your religion? } \\ \text { 'never or very rarely' } & 0 \\ \text { 'sometimes, but less than once a month' } & 1 \\ \text { 'once a month or more' } & 2 \\ \text { 'once a week' } & 3\end{array}$

We use the information to construct a 4-point church attendance index, providing information about the level of church attendance at three points in time. ${ }^{3}$ We conduct two types of analysis (i) cross-section analysis for the latest survey conducted at age 42 where the dependant variable is given by the church attendance index in $2000, r_{i}$, and (ii) panel data analysis

\footnotetext{
${ }^{3}$ It is important to acknowledge that our index of church attendance is a proxy for time spent in religious activities. Time spent on other religious activities such as praying is clearly omitted from our dependent variable.
} 
where we pool the information for individuals across the three time periods $(1981,1991$ and 2000) in order to explore how church attendance, $r_{i t}$, varies over an individual's life cycle.

\section{Cross-Section Analysis}

Given the nature of the dependent variable we initially specify an ordered probit model:

$$
r_{i}^{*}=\beta_{0}+\beta_{1} e_{i}+\boldsymbol{\varphi}^{\prime} \boldsymbol{X}_{i}+\varepsilon_{i}
$$

where $r_{i}^{*}$ is the unobservable propensity of individual $i$ to attend church; $r_{i}$ is the individual's observed church attendance; $e_{i}$ denotes the educational attainment of individual $i$ and $\boldsymbol{X}_{i}$ denotes a vector of personal and demographic characteristics. ${ }^{4}$ In order to explore the dynamic dimension to the church attendance decision, we include two lagged dependent variables - one denoting church attendance at age 33 and the other denoting church attendance at age 23 . Our cross-section data set pertaining to 2000, i.e. age 42, comprises 6,913 individuals.

Turning to the explanatory variables, educational attainment can be measured via a variety of approaches. We compare two commonly used measures - namely years of education and highest educational qualification obtained. In the initial analysis, we specify educational attainment as an exogenous explanatory variable in the religious activity equation. Following Sander (2002), we then allow for the possibility that educational attainment may be endogenous with respect to religious activity. Thus, we incorporate an educational attainment equation into our empirical analysis and replace $e_{i}$ with its predicted value, $\hat{e}_{i}$ as follows:

$$
\begin{aligned}
& e_{i}=f\left(\boldsymbol{Z}_{i}\right)+\lambda_{i} \\
& r_{i}^{*}=\beta_{0}+\beta_{1} \hat{e}_{i}+\boldsymbol{\varphi}^{\prime} \boldsymbol{X}_{i}+\varepsilon_{i}
\end{aligned}
$$

\footnotetext{
${ }^{4}$ In an ordered probit model, the probability that the observed outcome $j$ (there are 4 outcomes, see above) is in the range of the estimated cut-off points, $\mu_{j}$, is given by $\operatorname{pr}\left(r_{i}=j\right)=\operatorname{pr}\left(\mu_{j}-1<\beta_{0}+\beta_{1} e_{i}+\boldsymbol{\varphi}^{\prime} \boldsymbol{X}_{i}+\varepsilon_{i} \leq \mu_{j}\right)$.
} 
In order to create the predicted values of education, the functional form of Equation 2a differs according to our definition of educational attainment. In the case of years of education, we adopt a standard $O L S$ approach whilst in the case of highest educational qualification obtained, we follow Dearden et al. (2002) by adopting an ordered probit model given that educational attainment can be described by a single index. ${ }^{5}$ Our highest educational attainment index is defined on a 7-point scale with zero representing no educational qualifications, 1 denotes CSE level education (a relatively 'low' school qualification taken at age 16), 2 denotes $O$ level (a relatively 'high' school qualification taken at age 16), 3 denotes A level (the school qualification taken at age 18), 4 denotes diploma (i.e. intermediate qualifications between high school and university degree), 5 denotes degree (i.e. a Bachelors degree) and 6 denotes a higher degree (i.e. a Masters degree or a $\mathrm{PhD}$ ).

There has been much recent interest in the economics literature and amongst policymakers into the determinants of educational success with attention being paid to the relationship between school quality and academic performance. Thus, we draw upon this literature in order to specify our educational attainment equation, Equation 2a. The explanatory variables, given in $\boldsymbol{Z}_{i}$, are divided into three groups; school quality, family background and ability and largely build upon the specifications of Dearden et al. (2002) and Dustmann et al. (2003).

We adopt one of the standard measures of school quality - the number of pupils per teacher in the school at both the primary (i.e. pre age 11) and secondary (i.e. post age 11) stages of education. We also include dummy variables to control for whether, at the age of 16, the individual attends a secondary modern school, a technical school, a comprehensive school (i.e. non selective and state run), a grammar school (higher ability and state run) or a private school. We also control for whether the individual attended a single sex school at age

\footnotetext{
${ }^{5}$ Heckman and Cameron (1998) analyse the validity of such an approach.
} 
16. Controls also include a dummy variable denoting the presence of a parents-teachers association as well as a set of dummy variables indicating whether the school lacks library, sports or other facilities - factors excluded by Deardon et al. (2002) but which arguably could impinge upon educational attainment.

Family background has been found to be an important determinant of educational attainment [see Ermisch and Francesconi (2001)]. We incorporate a variety of controls for family background given that it may influence educational attainment through a number of different channels - for example through time inputs or financial resources. Family background variables include parents' occupation, years of education of parents and household income. The number of older siblings and the number of younger siblings are incorporated to explore the argument of Becker (1981) that parental attention declines as family size increases and to also explore the hypothesis that birth order is important. We also include information indicating whether the teacher considers the mother and/or father to be interested in the child's education at the age of 16 . In order to further proxy for family resources, we include a dummy variable indicating whether the individual has a private room for studying at age 16. We also include dummy variables indicating whether the child received free school meals at ages 11 and 16. In addition to controlling for whether the families experienced financial difficulties, we augment the approach adopted by Dearden et al. (2002) by also controlling for other difficulties faced by the families such as alcoholism in the family, death of mother or father and divorce.

In order to proxy ability, we include the individuals' scores attained in reading and mathematics tests at ages 7,11 and 16 . We are also able to proxy the child's attitude towards school, by including a dummy variable which equals one if he/she was truant at least once when aged 16. 
Returning to the religious attendance equation (Equation $2 \mathrm{~b}$ ) and the explanatory variables in the $X_{i}$ vector, we include a number of controls in addition to education in our church attendance equation. These include religious denomination, gender, being disabled, marital status, household size (including presence of pre-school and other children) and ethnicity. ${ }^{6}$ One serious omission from our data set relates to information pertaining to parents' religion and religious upbringing. In order to control for the stock of religious human capital as a child, we are, however, able to incorporate a dummy variable indicating whether the individual has a CSE, O level or A level in Religious Education. In order to explore the arguments put forward by Barro and McCleary (2002), we also incorporate a dummy variable indicating whether the individual has a CSE, O level or A level qualification in a science subject.

A set of variables related to economic status is incorporated in the specification including total income and total income squared (this includes labour and non labour income). Hence, we explore the argument discussed by Iannaccone (1998) that the opportunity cost of church attendance increases with income. Controls for labour market status are included by incorporating dummy variables for unemployment and self-employment as well as whether the individual's spouse is unemployed. We follow Ellison (1993) in incorporating measures of health and life satisfaction to explore the argument that higher rates of religious activity are associated with increased life satisfaction, improved health and reduced stress. We also include a dummy variable, which indicates whether the individual feels that he/she has someone to turn to for support. An index denoting how close the individual feels that the members of the household are is also added to the model. Following Sacerdote and Glaeser (2002), we include two variables representing the extent of participation in other formal social

\footnotetext{
${ }^{6}$ Note that age is excluded from the empirical specification since all individuals are of equal age.
} 
group activities such as attendance at political party meetings, charity and voluntary group meetings and attendance at women's groups.

In order to explore the effects of past religious activity on current religious activity, we include two lagged dependent variables - one denoting church attendance at age 33 and the other denoting church attendance at age 23. Past religious activities may be positively associated with current religious activities since according to Smith et al. (1998):

\footnotetext{
'...religious human capital and participation are complements since past and present consumption will be positively related. Moreover, the accumulation of religious human capital provides an incentive for further religious participation, which in turn augments that capital stock. This complementarity generates the habitual character of church attendance.' [Smith et al. (1998), p.29].
}

Thus, according to such arguments, the dynamic aspect to participation in religious activities is influenced by the accumulation of experience in religious activities such as knowledge and understanding of certain rituals or familiarity with hymns and prayers. In other words, the higher the levels of human capital acquired by participation in religious activities in the past, the more likely is an individual to continue to engage in religious activities. This is an important expansion of the current literature which has explored the relationship between individual religious attendance and education using cross-section data and, thus, has not focused on the dynamic dimension to religious activity [see, for example, Sawkins et al. (1997), Iannaccone (1998), Glaeser and Sacerdote (2002), and Sander (2002)].

\section{Panel Data Analysis}

Given that the NCDS provides information relating to church attendance at three points of an individual's life cycle, we are able to construct a panel of data at the individual level. In general, the existing studies in this area exploit cross-section data and are, thus, unable to analyse how an individual's religious activity varies over his/her life cycle. We explore a balanced panel of data, which comprises of those individuals who participated in all three surveys at ages 23,33 and 42 . We have 6,834 individuals who participated in all three surveys 
yielding a total of 20,502 observations. Given the nature of the dependant variable, we adopt a random effects ordered probit estimator.

In the following random effects ordered probit model, the dependant variable, $r_{i t}$, represents the church attendance index:

$$
\begin{aligned}
& r_{i t}^{*}=\beta_{0}+\beta_{1} e_{i t}+\boldsymbol{\varphi}^{\prime} \boldsymbol{X}_{i t}+v_{i t} \\
& v_{i t}=\alpha_{i}+\eta_{i t}
\end{aligned}
$$

where $r_{i t}^{*}$ is the unobservable propensity of individual $i$ to attend church at time period $t ; r_{i t}$ is the individual's observed church attendance; $\boldsymbol{X}_{i t}$ is a vector of exogenous characteristics which are expected to influence $r_{i t}{ }^{*} ; \boldsymbol{\varphi}$ is the associated vector of coefficients; $e_{i t}$ represents the individual's educational attainment; $\beta_{1}$ is the coefficient representing the impact of education on church attendance; $\alpha_{i}$ is the 'individual' specific unobservable effect which captures differences in propensity of church attendance; and $\eta_{i t}$ is a random error term. We assume a random effects specification, where $\eta_{i t} \sim \operatorname{IN}\left(0, \sigma_{i}^{2}\right)$, and in order to marginalise the likelihood it is assumed that, conditional on $e_{i t}$ and $\boldsymbol{X}_{i t}, \alpha_{i}$ are $\operatorname{IN}\left(0, \sigma_{\alpha}^{2}\right)$ and are independent of the $\eta_{i t}$ and the $\boldsymbol{X}_{i t}$. This implies that the correlation between the error terms of individuals is a constant given by:

$$
\rho=\operatorname{corr}\left(v_{i l}, v_{i k}\right)=\frac{\sigma_{\alpha}^{2}}{\sigma_{\alpha}^{2}+\sigma_{\eta}^{2}} \quad l \neq k
$$

Thus, $\rho$ represents the proportion of the total variance contributed by the panel level variance component. A fuller discussion of the random effects probit model and the associated likelihood function can be found in Arulampalam (1999). The likelihood is computed using a 20 point Gauss-Hermite quadrature [see Butler and Moffitt (1982)]. The random effects framework allows us to establish how much of the variation in the data can be explained by 
unobservable intra-individual correlations. Thus, the magnitude of $\rho$ provides information pertaining to whether individuals are likely to report consistent levels of religious activity across the three time periods, conditional upon the underlying covariates, or whether religious activity is subject to much change over the individual's life cycle. The analysis of panel data is particularly appropriate for exploring rates of religious behaviour since age has been found to be a particularly strong indicator of religious activity with religious activity increasing with age [see, for example, Iannaccone (1998), Sander (2002) and Sawkins et al (1998)]. Such findings may be explained by habit formation and/or the importance of afterlife expectations over time.

In order to illustrate how church attendance varies over the life cycle, Table $1 \mathrm{~A}$ in the Appendix presents cross-tabulations between church attendance in 1981 (i.e. age 23) and in 1991 (i.e. age 33) and between 1991 and 2000 (i.e. age 42). The shaded boxes along each diagonal highlight the extent to which church attendance does not change over time. Between the ages of 23 and 33 around $67 \%$ of individuals do not change the frequency of attendance, with the remaining 2,255 individuals (shown in the off-diagonal elements) generally reducing attendance - notably with a large increase in attending church 'sometimes, but less than once a month' (category 1 with 1,061 individuals). A similar pattern emerges if we focus upon attendance between 33 and 42 with $66 \%$ of individuals not changing their frequency of attendance. It is also apparent that attendance at the highest and lowest levels are the most time invariant whilst the intermediate levels of church attendance are subject to more change over time. Notably between the two periods depicted in Table 1A, over the life cycle individuals appear to attend church less $-61.7 \%$ 'never or rarely attended church' (category 0) compared to $71.1 \%$ in the later period. 
We also explore the possibility that education may be endogenous in the context of our panel data analysis. Hence, we estimate the following: ${ }^{7}$

$$
\begin{aligned}
& e_{i t}=g\left(\boldsymbol{Z}_{i t}\right)+\lambda_{i t} \\
& r_{i t}^{*}=\beta_{0}+\beta_{1} \hat{e}_{i t}+\boldsymbol{\varphi}^{\prime} \boldsymbol{X}_{i t}+v_{i t}
\end{aligned}
$$

The set of explanatory variables in $\boldsymbol{X}_{i t}$ is similar to that used in the cross-section analysis comprising of a mixture of time varying variables (such as marital status and economic activity) and time invariant information (such as ethnicity). It is also apparent that the religious denomination dummies may change over time as individuals switch in and out of different religions. Iannaccone (1998) argues that we would expect to see the extent of such switching to decline over an individual's lifetime. ${ }^{8}$ Table 1B in the Appendix presents crosstabulations between religious denomination in 1981 (i.e. age 23) and in 1991 (i.e. age 33) and between 1991 and 2000 (i.e. age 42), thus giving an insight into the dynamics of religious denomination. The shaded boxes along each diagonal highlight the extent to which religious denomination does not change over time. For example, between the ages of 23 and 33 approximately $65 \%$ of individuals are Church of England (category 1 with 1,592 individuals). Interestingly there is some variation over time, but as Iannaccone (1998) argued such switching between denominations does fall over time. This is evident if we focus upon each denomination between the ages of 33 and 42 where it is apparent that each figure along the lead diagonal is greater than the counter-part for earlier in the life cycle i.e. aged 23 and 33.

The following section presents the results of the cross-section and panel data analysis focusing on our main question of investigation, i.e. whether educational attainment has a

\footnotetext{
${ }^{7}$ Again the functional form of $g(\cdot)$ in Equation 5a depends on how we define education. If education is measured by years of schooling then the model is estimated by $O L S$ or if the hierarchy of qualifications is used an ordered probit model is specified.

${ }^{8}$ A small number of variables were omitted from the panel data analysis due to inconsistencies in the questions posed across the three surveys. These include the happiness index, whether the individual works for a charity, attendance at other formal social activities, the perceived index of support and the variable controlling for how close the individual believes his/her family is.
} 
positive or negative effect on religious attendance, i.e. $\beta_{1} \geq 0$ or $\beta_{1} \leq 0$. Full summary statistics relating to both the cross-section data and the panel data are presented in Table 2 in the Appendix.

\section{Results}

\section{Cross-Section Results}

\section{Exogenous Education}

Table 3 in the Appendix presents the results derived from the cross-section analysis of the determinants of church attendance at age 42 where education is included as an exogenous explanatory variable. In order to explore the robustness of our cross-section findings, we present six different specifications. Specifications 1 and 2 incorporate highest educational qualifications whilst specifications 3 to 6 are based on years of education. Specifications 2, 4 and 6 also include past church attendance, i.e. church attendance at ages 23 and 33, in order to ascertain whether a dynamic dimension to church attendance exists. ${ }^{9}$

It is apparent from specifications 1 and 2 that educational attainment at the upper end of the hierarchy, i.e. degrees (undergraduate and postgraduate) and having a diploma, are positively associated with church attendance. Lower levels of education, on the other hand, appear to have no significant impact on church attendance, with the exception of CSE only education, which is negatively related to attendance. It is also apparent from Table 3 that years of education, the alternative measure of educational attainment, are positively related to church attendance.

The sizes of the estimated coefficients on the educational attainment variables (higher degree, degree and diploma) are somewhat reduced, however, once past religious activity is incorporated into the analysis. It is clear that past levels of church attendance are strongly

\footnotetext{
${ }^{9}$ For reasons of brevity, we do not present the marginal effects, although these are available from the authors on request.
} 
positively related to current church attendance with the association being heightened over time. Thus, our findings support the argument of Smith et al. (1998) that the accumulation of religious human capital provides an incentive for future religious activity. This has not been addressed in the literature to date due to the predominant use of cross-section data. This argument is also supported by the significant and positive estimated coefficient on the dummy variable indicating whether the individual has an $\mathrm{O}$ or A level in Religious Education. Once again, this finding is robust across the six different specifications. The findings related to the possession of an $\mathrm{O}$ or $\mathrm{A}$ level in a science subject, however, follow a much less distinct pattern in terms of statistical significance but are always negatively signed. This finding provides some support for the claim that individuals become more sceptical of faith-based claims as they acquire education in science based subjects [see Iannaccone (1998)].

Our findings with respect to gender tie in with the existing literature in that females are found to exhibit higher levels of church attendance than males [see, for example, Iannaccone (1998), Sawkins et al. (1997) and Brañas Garza and Neuman (2003)]. Various arguments have been put forward to explain the finding that women appear to be 'more religious' than men. For example, it may be the case that the opportunity cost of time is lower for women due to lower wages and/or less employment opportunities. The finding may, on the other hand, be due to gender-based personality characteristics. Whilst the sign of the estimated coefficient on the gender dummy variable is consistent across the specifications, the size of the estimated coefficient is subject to a degree of variability being less pronounced when past levels of church attendance are controlled for.

Turning to the other personal characteristics, there appears to be some differences in the level of church attendance across ethnic groups. Being black, for example, is strongly positively correlated with church attendance, which accords with the findings of Azzi and Ehrenberg (1975). Marital status also appears to be an important determinant of church 
attendance with church attendance being positively related to being married - a finding, which once again ties in with the existing literature [see Iannaccone (1998)]. Individuals who are separated, widowed or divorced are also more likely to attend church. Similarly, the presence of pre-school children in the household is positively associated with church attendance whilst having older children appears to exert an insignificant influence.

We also include a number of other variables related to individuals' perceptions about social networks such as whether the individual feels that he/she has someone to turn to for support and how close he/she feels their family is. These variables, however, turned out to be insignificantly related to church attendance. In contrast to Ellison (1993), we find that the happiness index used to proxy life satisfaction and the health index are also insignificant. Our findings do, however, provide some support for the hypothesis of Glaeser and Sacerdote (2002) in that church attendance is positively related to attendance at other formal group social activities. Moreover, these findings are highly significant and robust across the six specifications. $^{10}$

Our findings also suggest that economic status does not affect religious attendance. In particular, being unemployed or self-employed have insignificant effects upon church attendance, whilst total household income is also found to be insignificantly related to church attendance. Controls for whether the individual has an unemployed partner also turn out to be insignificant across specifications.

Finally, religious denomination is clearly an important determinant of church attendance with Non-Christians and Roman Catholics being characterised by the largest positive and most statistically significant estimated coefficients. In specifications 5 and 6 ,

\footnotetext{
${ }^{10} \mathrm{We}$ also investigated the relationship between educational attainment and other forms of social engagement. This essentially involved adopting the same methodology as outlined in Section III but with other measures of social attendance as the dependent variable, specifically: attendance at political party meetings; charity and voluntary group meetings; and attendance at women's groups. In each model of social attendance, as measured by the different dependent variables (each ordered in the same way as the church attendance index), we found a positive and significant impact of education upon attendance in accordance with Glaeser and Sacerdote (2002).
} 
however, when religious denomination is interacted with years of education, we find that the Church of England denomination interaction is characterised by the most robust positive influence.

\section{Endogenous Education}

In Table 4, we repeat our cross-section analysis but replace the highest educational dummy variables and years of education with their predicted values as derived from the educational attainment equation outlined in Section III [see Equations 2a and 2b]. ${ }^{11}$ Table 4 has the same format as Table 3 with six specifications reported. In general, our findings are unchanged and, hence, for reasons of brevity we will only comment on those variables, which are the focus of our paper - namely education and past levels of religious activity. It is apparent from Table 4 that the positive association between educational attainment and church attendance remains once educational attainment is treated as an endogenous variable. Furthermore, the sizes of the estimated coefficients on education are much larger when education is treated as an endogenous variable.

Thus, our findings contrast with those of Sander (2002) for the U.S. who finds no causal effect of education on religious activities. In addition, we also find that the relationship between current and past church attendance is robust to such changes with past levels of religious activity being positively and strongly correlated with current church attendance. In terms of the denomination interactions with years of schooling, i.e. specifications 5 and 6 ,

\footnotetext{
${ }^{11}$ For reasons of brevity, we do not present the results pertaining to the two educational attainment equations. In general, the two equations are well-specified and our findings accord with the existing literature and a priori expectations. For example, the pupil-teacher ratio is found to be a significant determinant of educational attainment. Attending a grammar school is positively related to educational attainment. Family background is found to be an important determinant of education - for example parent's years of education and whether the parents express an interest in their child's education are both positively associated with educational attainment. Ability as proxied by test scores in maths and English at ages 7,11 and 16 are all positively related to educational attainment. Full results are available from the authors on request.
} 
again the Church of England interaction dominates and is significant, as found under the exogenous education model. ${ }^{12}$

\section{Panel Data Results}

In Table 5 in the Appendix, we present our estimates of Equations 3, 5a and $5 \mathrm{~b}$ for our balanced panel of data. We omit the explanatory variables related to past religious behaviour, as these become observations in our panel of data. In the first specification, it is apparent that educational attainment at all levels (with the exception of CSE only education) are positively associated with church attendance. Furthermore, the sizes of the estimated coefficients on the educational attainment variables increase as we move up the educational attainment hierarchy. In the next column, we endogenise the education attainment index. Our findings confirm the positive association between church attendance and educational attainment. In the final columns of Table 5, we explore the alternative measure of education, years of schooling. When treated as an exogenous or endogenous variable, our findings once again support a positive relationship between education and religion. As in the cross-section analysis, when religious denomination is interacted with years of education, we find that the Church of England denomination interaction is characterised by a positive influence. In addition, in contrast to the cross-section findings, there is clear support for the claim that individuals become more sceptical of faith-based claims as they acquire more education in science based subjects (i.e. Biology, Chemistry or Physics), since across the panel data specifications, the science dummy is characterised by a negative and significant estimated coefficient.

Finally, as mentioned in Section III, the magnitude of $\rho$ provides information pertaining to whether individuals are likely to report consistent levels of religious activity

\footnotetext{
${ }^{12}$ We have also conducted the analysis presented in Tables 3 and 4 for males and females separately. In general, the pattern of our results does not change. There are, however, some interesting differences between the findings for men and women. For example, the extent to which the positive association between past and current church attendance is heightened over time is much more pronounced amongst men. In addition, the impact of educational attainment on church attendance is greater for females than males - this is especially the case at higher levels of education. Full results are available from the authors on request.
} 
across the three time periods or whether religious activity is subject to much change over the individual's life cycle. Across all of the specifications presented in Table 5, it is apparent that $\rho$ is significant and, furthermore, the size of $\rho$ indicates that levels of church attendance are relatively consistent over the time period.

In order to explore whether levels of church attendance vary less towards the later stages of an individual's life cycle, we split our panel of data into two time periods - 1981 and 1991 (i.e. ages 23 and 33) and 1991 and 2000 (i.e. ages 33 and 42). Hence, we constructed two balanced panels of data, each with $2 \times 6,834$ (i.e. 13,668 ) observations. We then repeated our analysis of Table 5 for each of the two time periods. Table 6 presents the

values of $\rho$ estimated for each of the twelve regressions. It is apparent that the size of $\rho$ is much larger in the later time period suggesting that there is less variation in church attendance, as individuals become older. Such an effect may be due to, for example, habit formation over time. This supports the notion that church attendance varies less at later stages of the life cycle.

\section{Conclusion}

In this paper, we have contributed to the expanding area of the economics of religion, which is one area of household behaviour that has attracted very little interest in the economics literature. To be specific, we have explored the determinants of one measure of religious activity - church attendance - at the individual level using British panel data derived from the National Child Development Study. Moreover, we have focused on the relationship between church attendance and education, which has attracted some attention in the existing literature.

We have further developed the approach of Sander (2002), who treats education as an endogenous variable, in three main ways. Firstly, we have expanded the church attendance equation to incorporate a more extensive array of explanatory variables. Secondly, we have 
specified a more comprehensive educational attainment equation in order to control for endogeneity bias. Thirdly, we have analysed individual panel data thereby enabling us to explore religious activity from a dynamic perspective, i.e. at different points of an individual's life cycle - namely at ages 23,33 and 42 . In contrast to the previous literature in this area, our data has enabled us to ascertain whether a dynamic dimension to religious activity exists.

The findings from our cross-section and panel data analysis support a positive association between education and church attendance. In addition, our findings suggest that current participation in religious activities is positively associated with past religious activities. Furthermore, our results suggest that levels of religious activity tend to vary less over time suggesting that factors such as habit formation may be important. To summarise, our findings do suggest that a time dimension to religious activity exists. Furthermore, the importance of previous religious activity in determining current levels of religious activity suggests that omitting such factors from econometric analysis may lead to biased results and erroneous inferences.

Finally, as pointed out by Sacerdote and Glaeser (2002), the positive association between education and church attendance indicates that education plays an important role in social involvement. Such findings may inform Governments on the reasons behind social exclusion and may help to shape policies to alleviate social exclusion. It is apparent that education and schooling serve to affect involvement in formal social activities such as church attendance during adulthood. Thus, education clearly impacts upon many aspects of household behaviour both during childhood and adulthood and, thus, may help to enhance social inclusion. 


\section{References}

Arulampalam, W. (1999) 'Practitioners' Corner: A Note on Estimated Coefficients in Random Effects Probit Models,' Oxford Bulletin of Economics and Statistics, 61, 597602.

Azzi, C. and R. Ehrenberg (1975) 'Household Allocation of Time and Church Attendance,' Journal of Political Economy, 83, 27-56.

Barro, R. and R. McCleary (2002) 'Religion and Political Economy in an International Panel,' NBER Working Paper Number: 8931.

Becker, G. S. (1981) A Treatise on the Family, Cambridge: Havard University Press.

Brañas Garza, P. and S. Neuman (2003) 'Analysing Religiosity within an Economic Framework: The case of Spanish Catholics,' IZA Discussion Paper, Number 868.

Butler, J.S. and R. Moffitt (1982) 'A Computationally Efficient Quadrature Procedure for the One Factor Multinomial Probit Model,' Econometrica, 50, 761-64.

Dearden, L., J. Ferri and C. Meghir (2002) 'The Effect of School Quality on Educational Attainment and Wages,' The Review of Economics and Statistics, 84, 1-20.

Dustmann, C., N. Rajah and A. van Soest (2003) 'Class Size, Education and Wages,' The Economic Journal, 113, F99-F120.

Ellison, C. G. (1993) 'Religion, the Life Stress Paradigm, and the Study of Depression,' in Religion in Aging and Mental Health: Theoretical Foundations and Methodological Frontiers. Jeffrey S. Levin (Editor), Thousand Oaks: Sage, 78-121.

Ermisch, J. and M. Francesconi (2001) 'Family Matters: Impacts of Family Background on Educational Attainment,' Economica, 68, 137-56.

Glaeser, E. L. and B. I. Sacerdote (2002) 'Education and Religion,' NBER Working Paper Number: 8080. 
Heckman, J. and S. Cameron (1998) 'Life Cycle Schooling and Dynamic Selection Bias: Models and Evidence for Five Cohorts of American Males,' Journal of Political Economy, 106, 262-333.

Iannaccone, L. R. (1998) 'Introduction to the Economics of Religion,' Journal of Economic Literature, 36, 1465-95.

Neuman, S. (1986) 'Religious Observance within a Human Capital Framework,' Applied Economics, 18, 1193-1202.

Sander, W. (2002) 'Religion and Human Capital,' Economics Letters, 75, 303-7.

Sawkins, J. W., P. T. Seaman and H. C. S. Williams (1997) 'Church Attendance in Great Britain: An Ordered Logit Approach,' Applied Economics, 29, 125-34.

Smith, I., J. W. Sawkins and P. T. Seaman (1998) 'The Economics of Religious Participation: A Cross-Country Study,' Kyklos, 51, 25-43.

Stark, R., Iannaccone, L. and R. Finke (1996) 'Religion, Science and Rationality,' American Economic Review, AEA Papers and Proceedings, 86, 433-7. 


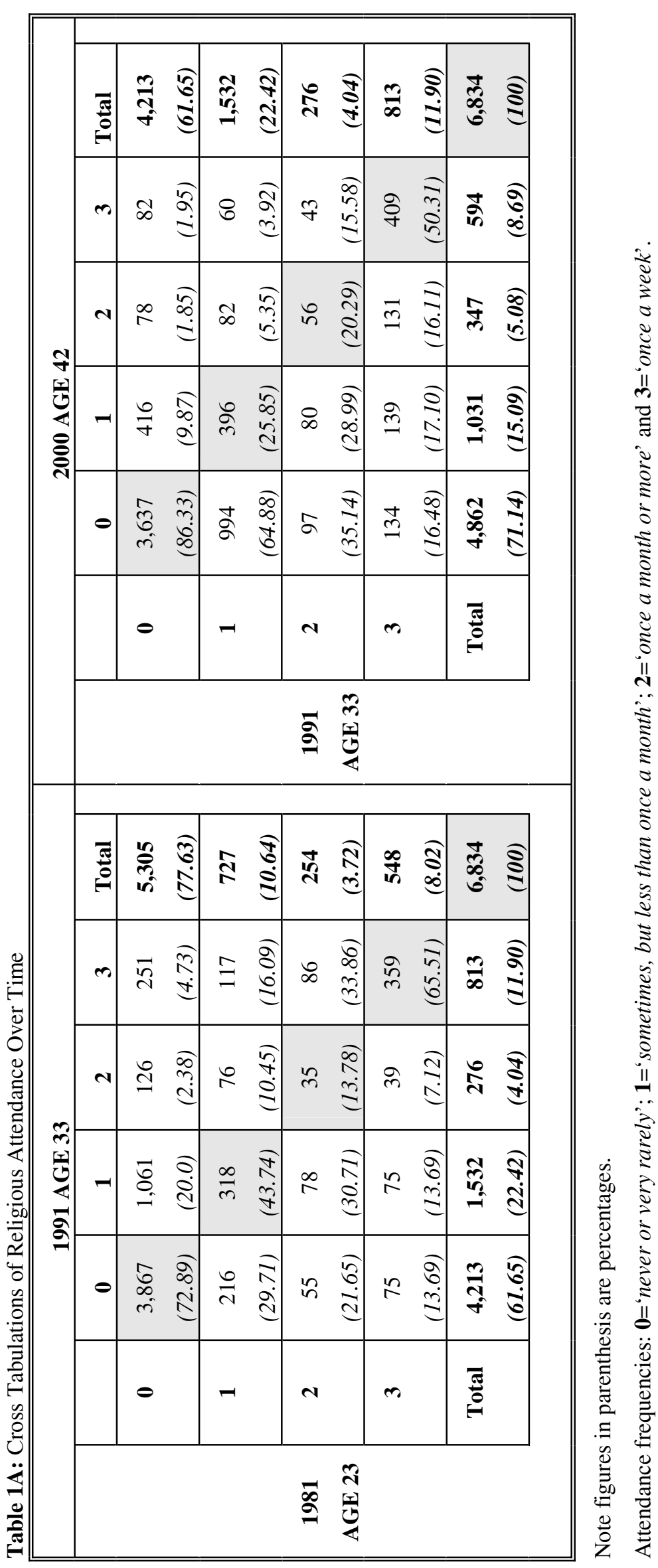




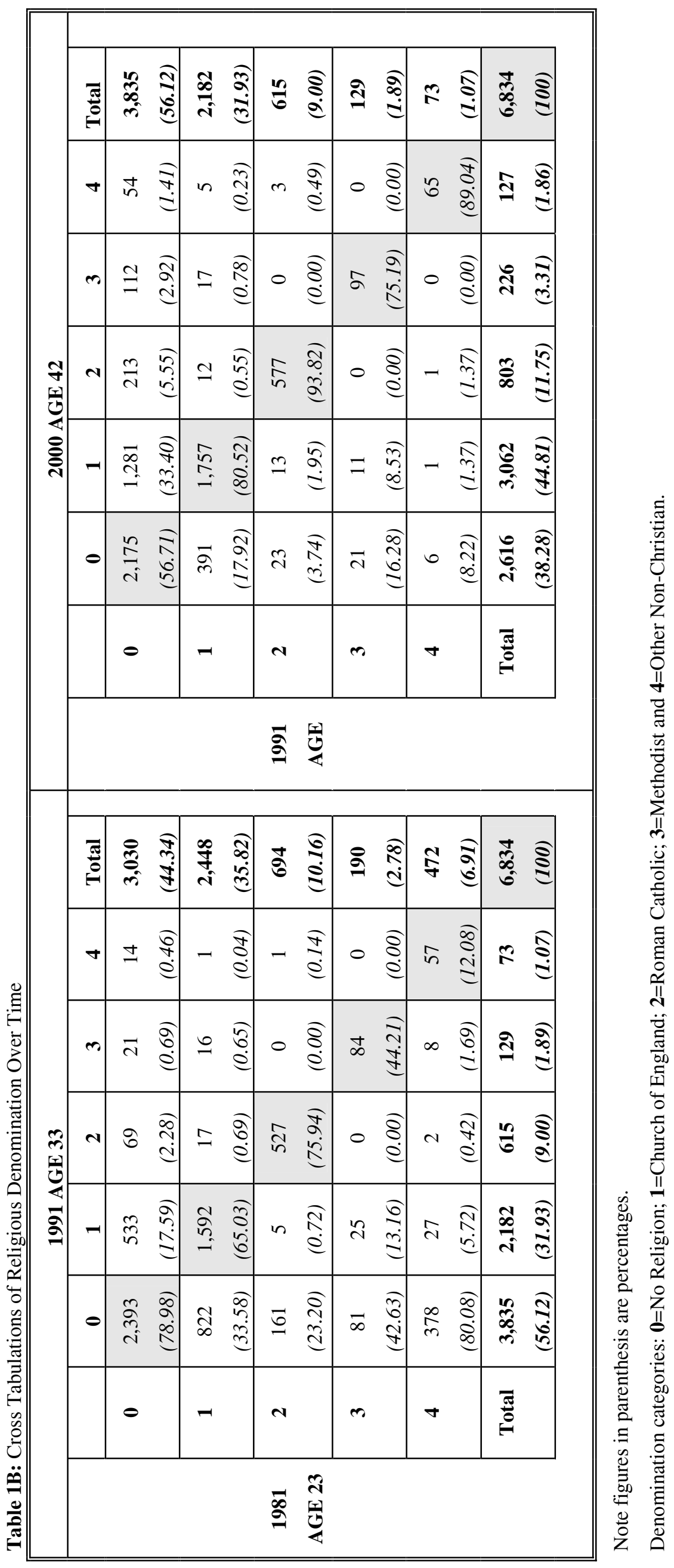




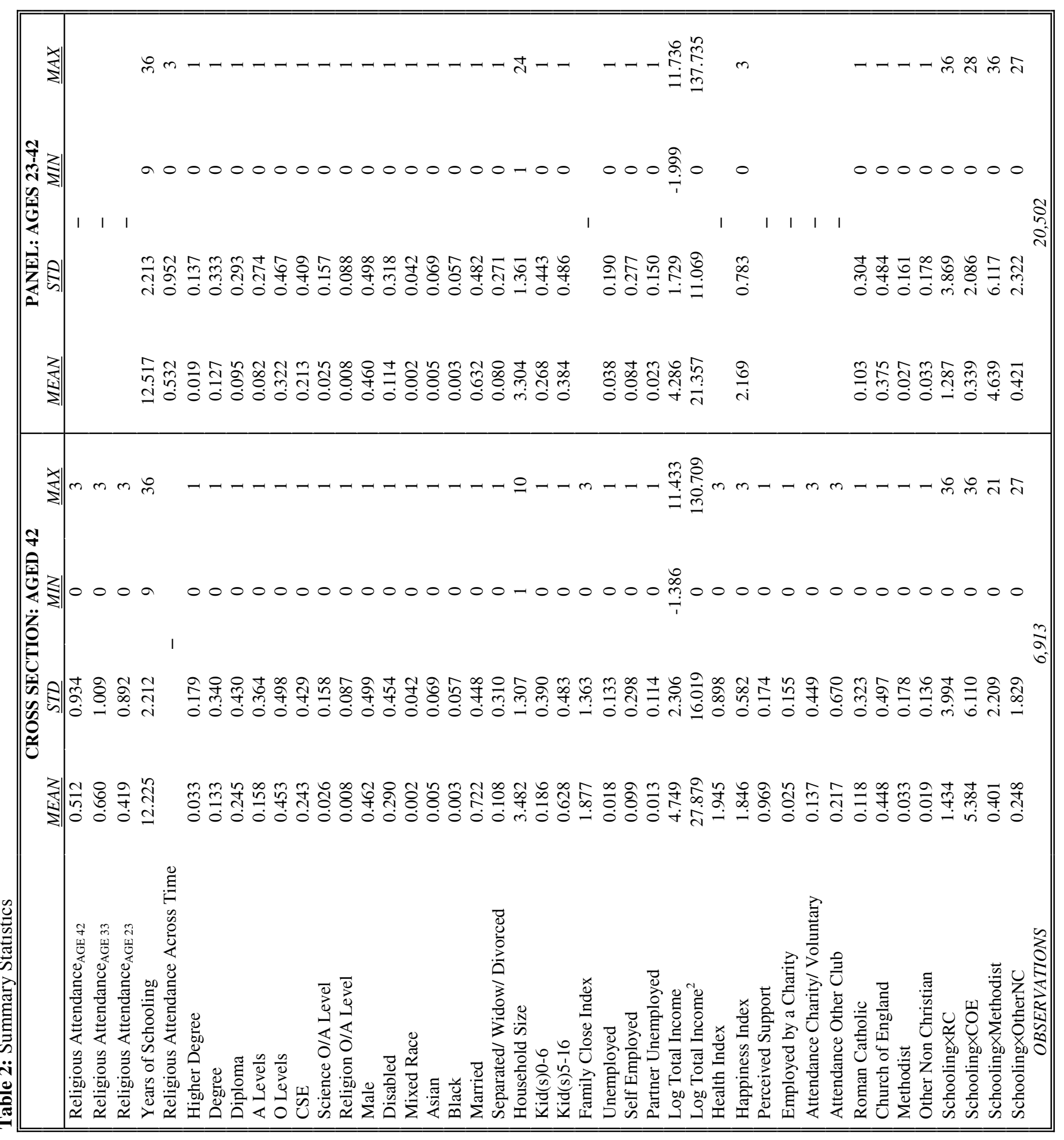




\begin{tabular}{|c|c|c|}
\hline & 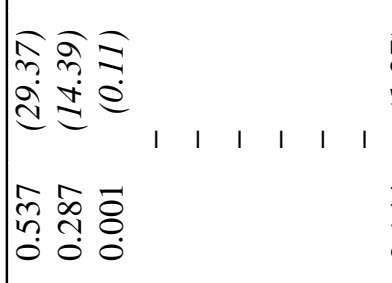 & 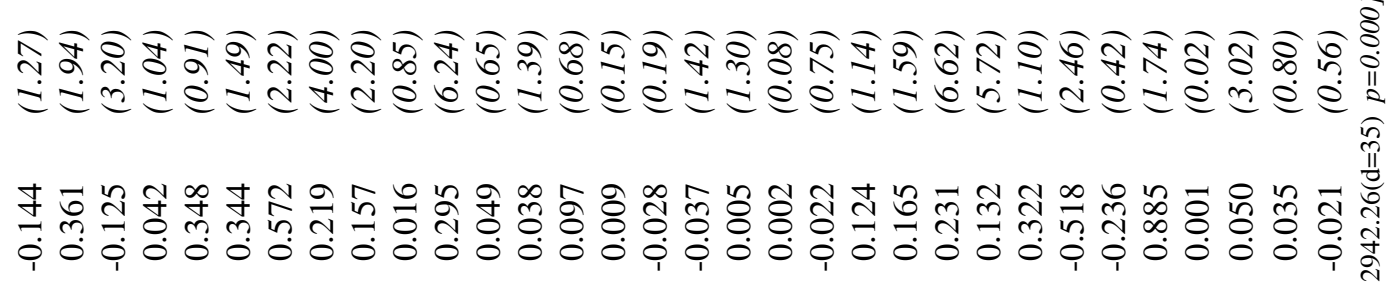 \\
\hline & 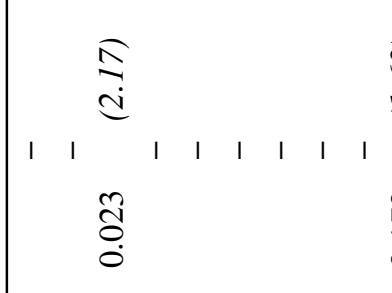 & 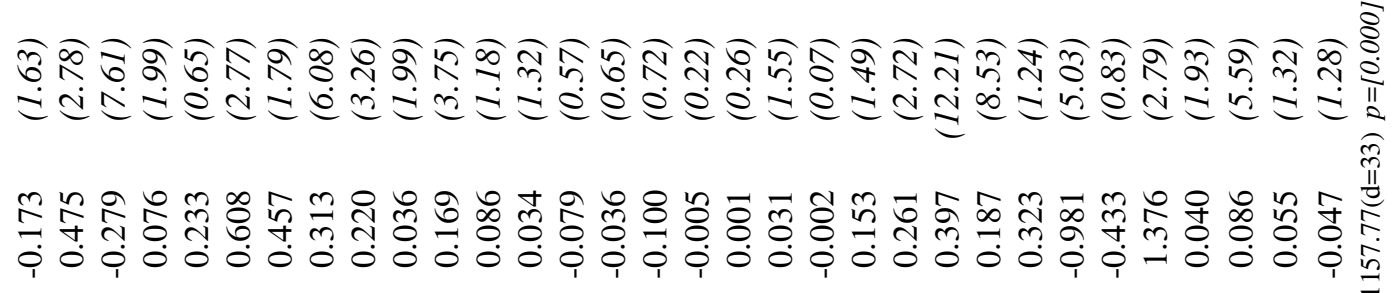 \\
\hline & 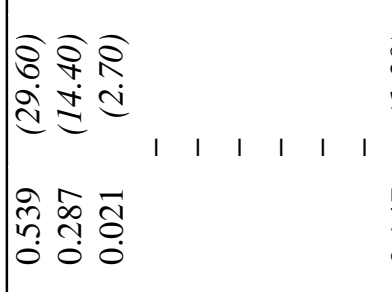 & 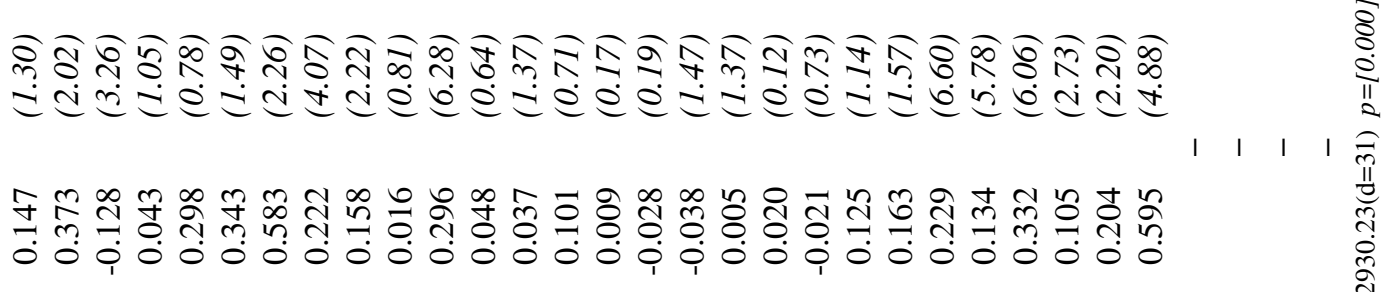 \\
\hline & 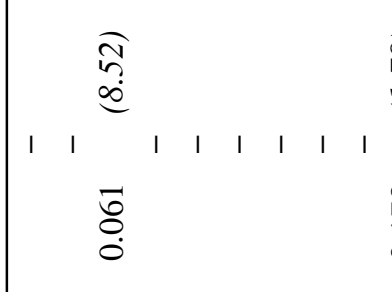 & 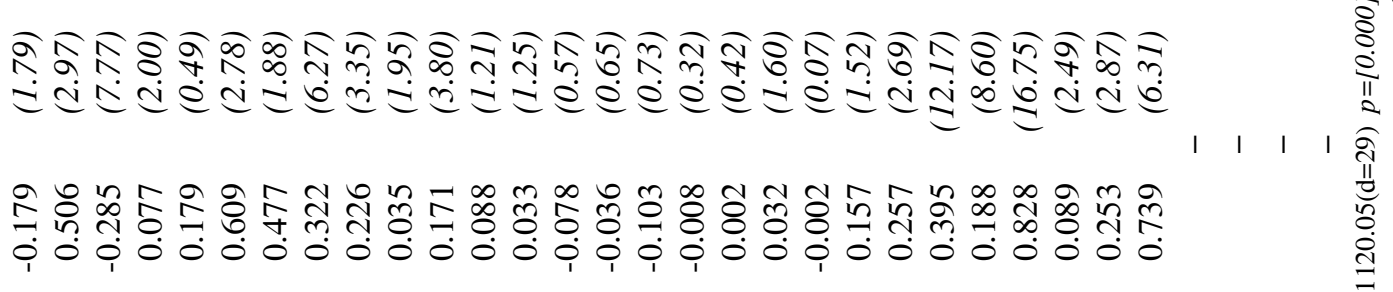 \\
\hline & 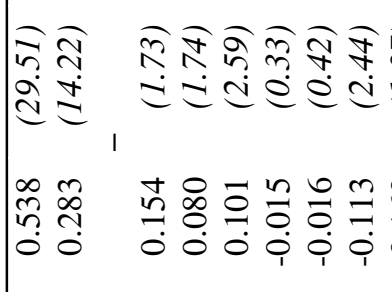 & 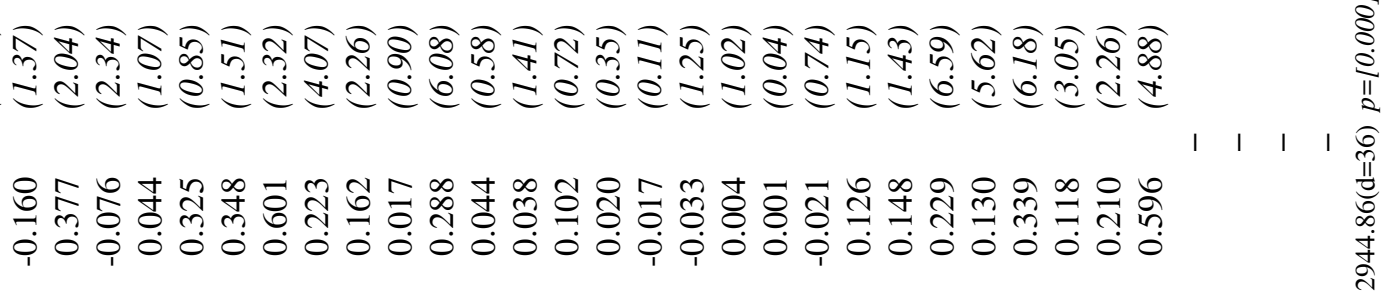 \\
\hline & 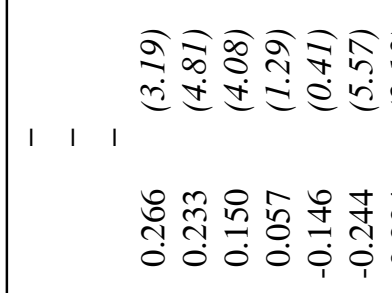 & 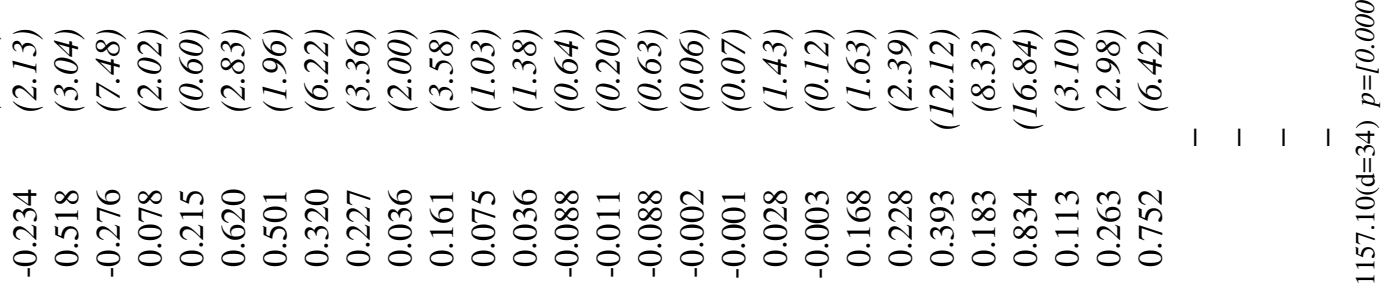 \\
\hline & 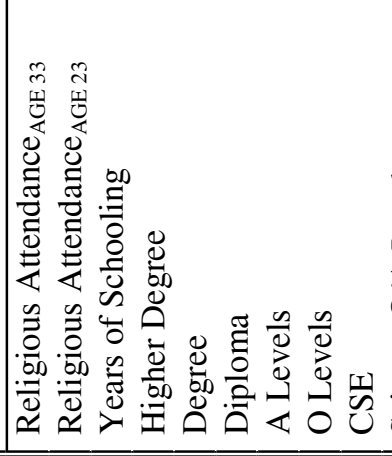 & 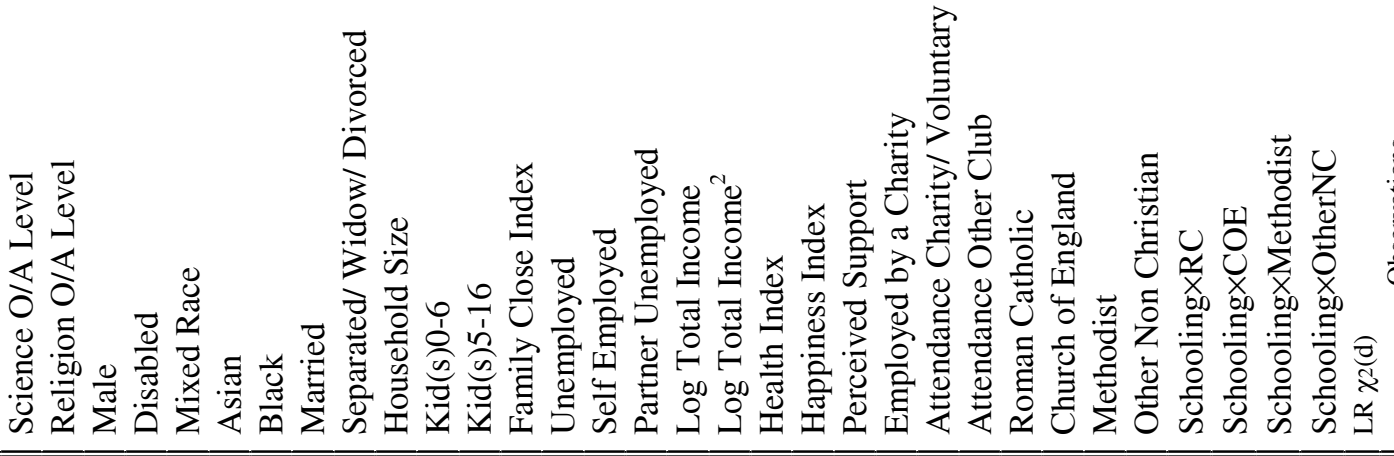 \\
\hline
\end{tabular}




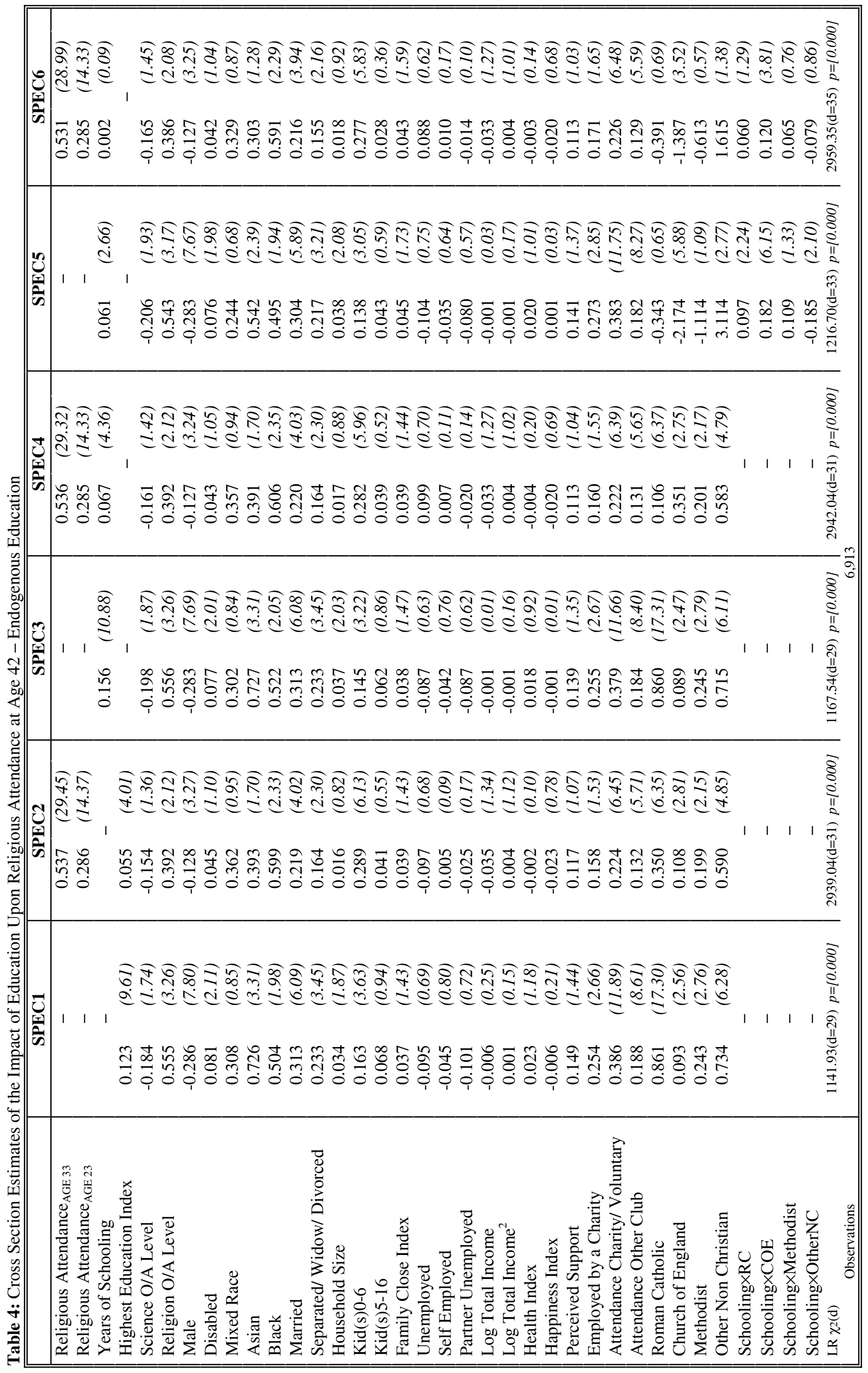




\begin{tabular}{|c|c|}
\hline 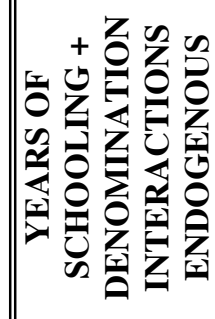 & 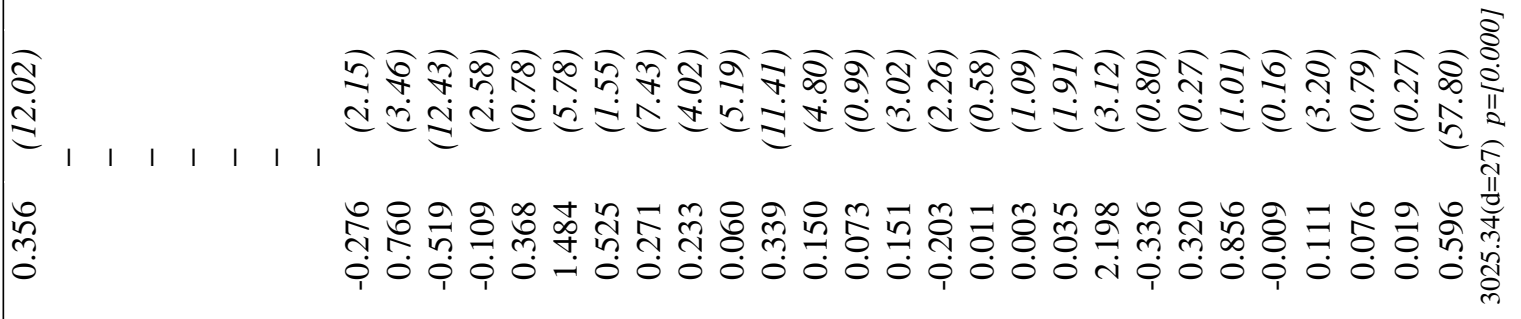 \\
\hline 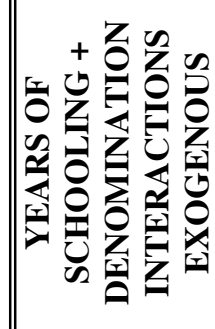 & 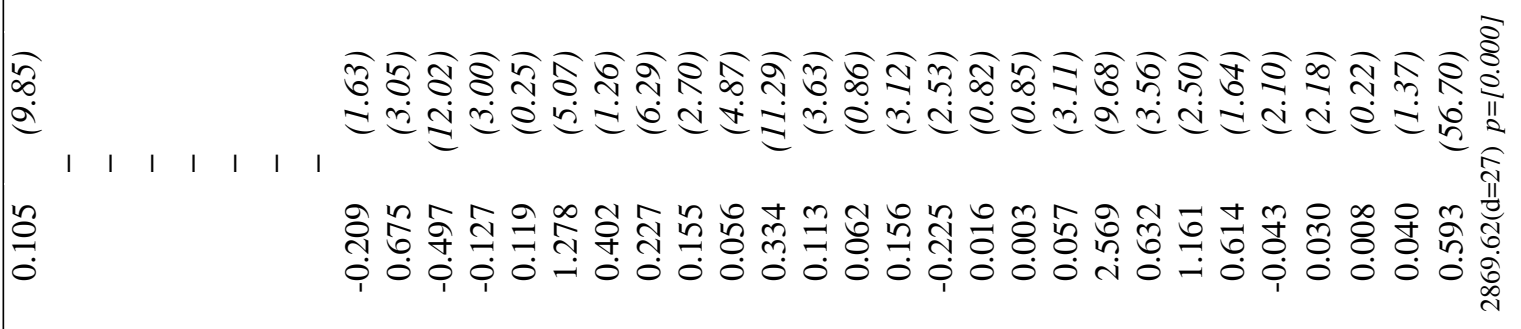 \\
\hline 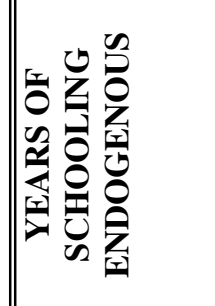 & 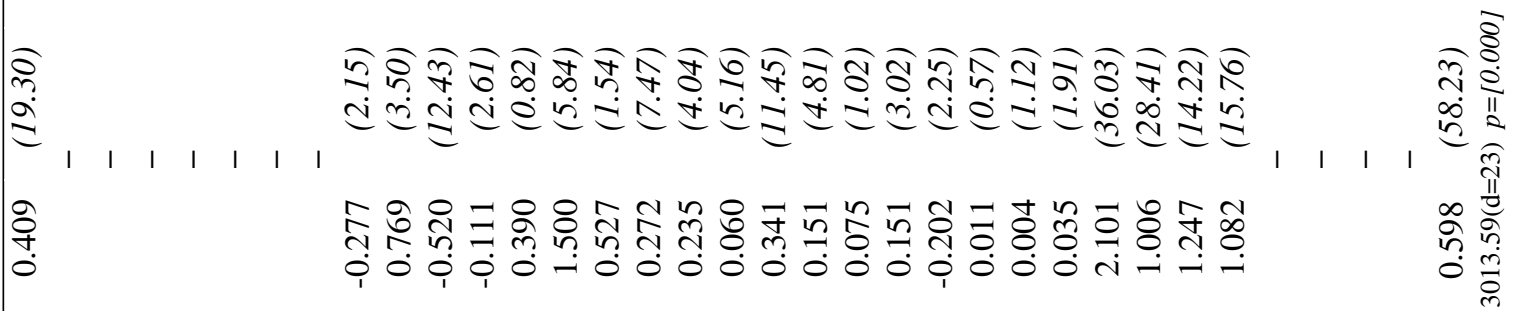 \\
\hline 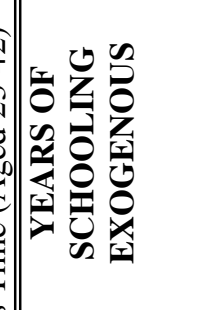 & 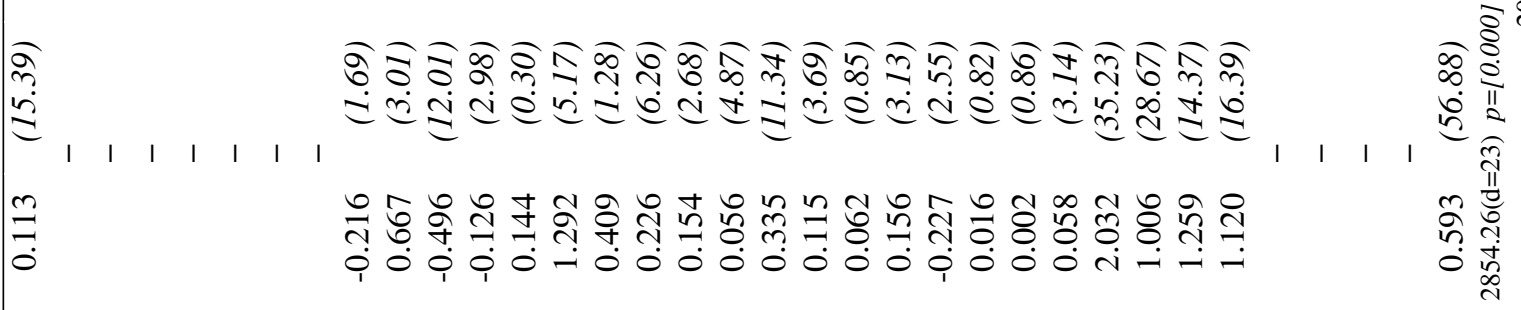 \\
\hline 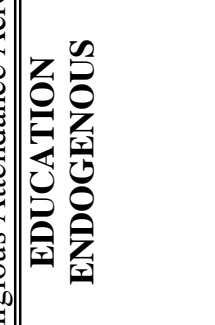 & 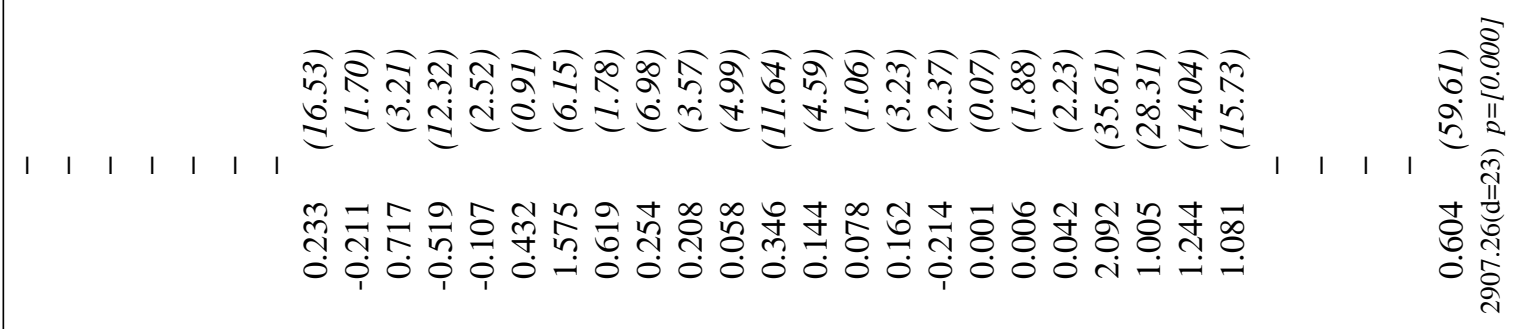 \\
\hline 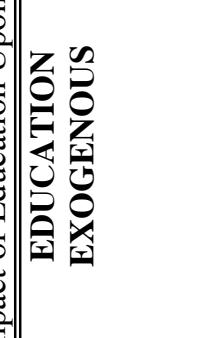 & 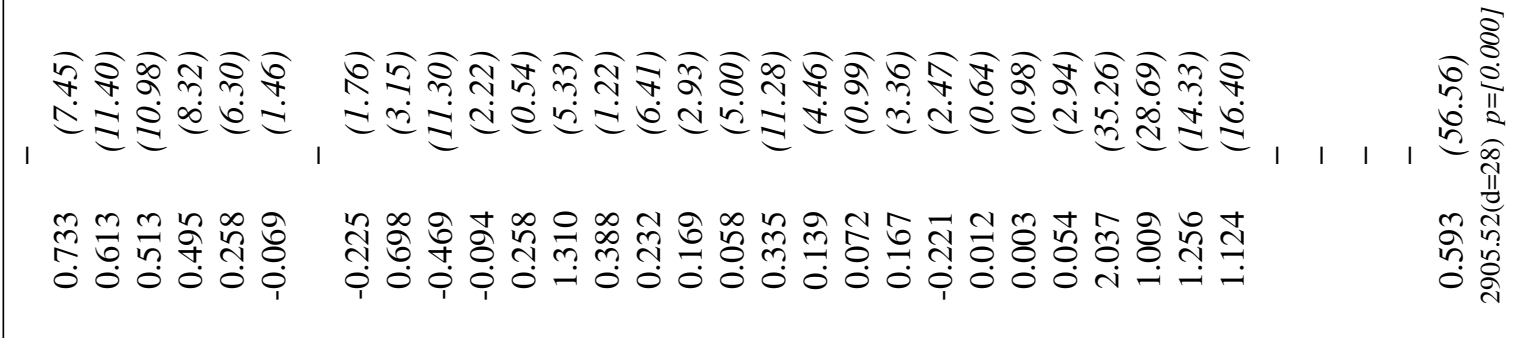 \\
\hline & 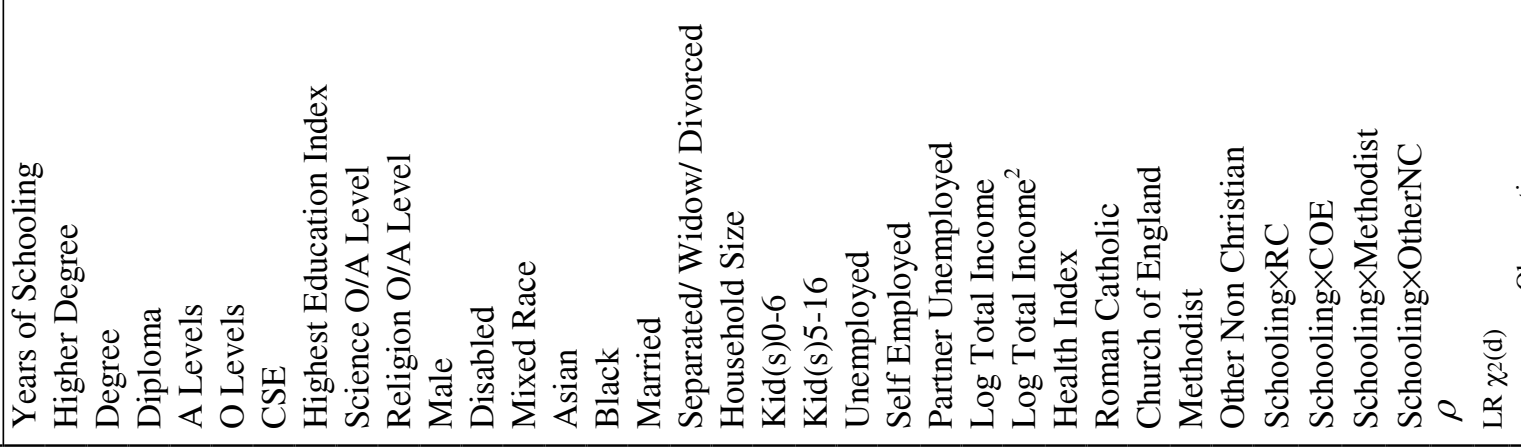 \\
\hline
\end{tabular}




\begin{tabular}{|c|c|c|c|}
\hline 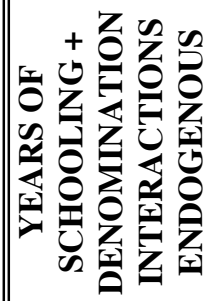 & 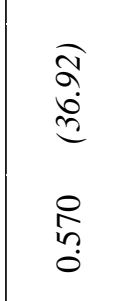 & & 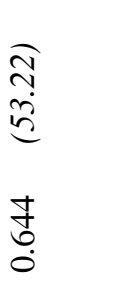 \\
\hline 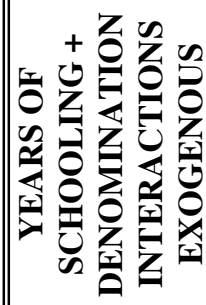 & 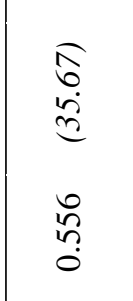 & & 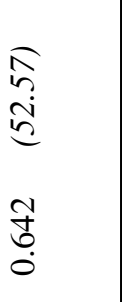 \\
\hline 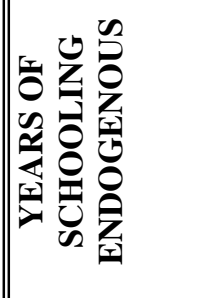 & 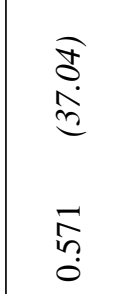 & & $\begin{array}{l}\widehat{\hat{\sigma}} \\
\dot{+} \\
\text { s. } \\
0 \\
0 \\
0 \\
0 \\
0\end{array}$ \\
\hline 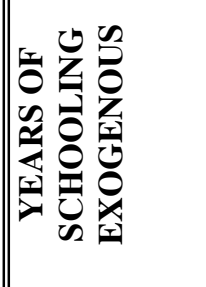 & $\begin{array}{l}\sqrt{n} \\
n \\
n \\
n \\
n \\
n \\
n \\
0\end{array}$ & & 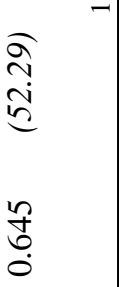 \\
\hline 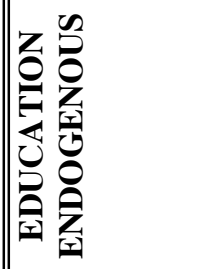 & $\begin{array}{l}\widehat{\approx} \\
\stackrel{n}{n} \\
\stackrel{\Sigma}{n} \\
\tilde{0}\end{array}$ & & 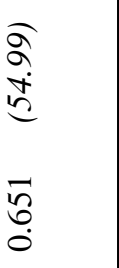 \\
\hline 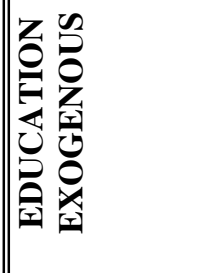 & 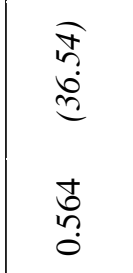 & & 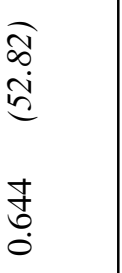 \\
\hline & 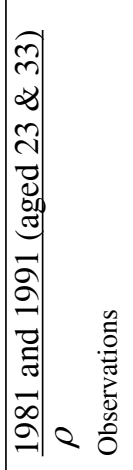 & 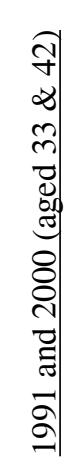 & 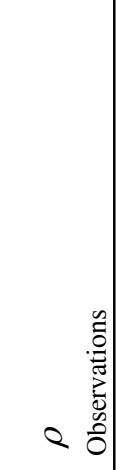 \\
\hline
\end{tabular}

